\title{
FOTODEGRADASI METHYL ORANGE DALAM REAKTOR FIXED BED BATU APUNG-SEMEN
}

\author{
N.W. Yuningrat ${ }^{1}$, N. Retug ${ }^{2}$, I.M. Gunamantha ${ }^{3}$ \\ 1,3 Jurusan Analis Kimia FMIPA \\ 2Jurusan Pendidikan Kimia FMIPA \\ Universitas Pendidikan Ganesha \\ Singaraja, Indonesia
}

E-mail: niwyuningrat@gmail.com,md_gunamantha@yahoo.com

\begin{abstract}
Abstrak
Tujuan penelitian ini adalah untuk mengetahui karakteristik batu apung dan semen yang digunakan sebagai bed dalam reaktor fixed bed dan efektivitasnya dalam mendegradasi methyl orange akibat pengaruh $\mathrm{pH}$ larutan dan sinar dalam sistem reaksi. Bed yang digunakan adalah batu apung berukuran kecil dengan perekatan semen dalam cetakan stainless steel berukuran $5 \times 16 \times 16 \mathrm{~cm}$. Fotodegradasi methyl orange dijalankan pada $\mathrm{pH}$ larutan 7 dan diberikan sinar 2 buah lampu UV Sankyo Denky FT10T8BLB FL10BLB 10 W 325 nm selama 1, 2, 3, 4, 5, 6 dan 7 jam. Methyl orange disirkulasi pada temperatur kamar dari tangki penampungan menuju reaktor fixed bed menggunakan pompa dengan debit sebesar 6,89 mL/detik. Batu apung dan semen yang digunakan sebagai bed dianalisis bentuk dan unsur yang dikandungnya dengan menggunakan SEM EDX. Konsentrasi methyl orange sebelum dan setelah proses fotodegradasi diukur dengan menggunakan spektrofotometer UV Visibel Shimadzu 1240. Hasil penelitian menunjukkan bahwa batu apung memiliki bentuk yang tidak beraturan dengan kandungan unsur tertinggi berupa Si sedangkan semen yang digunakan sebagai perekat memiliki bentuk seperti butiran yang homogen dengan kandungan unsur tertinggi $\mathrm{Ca}$. Fotodegradasi methyl orange berjalan optimum pada $\mathrm{pH} 3$ untuk waktu penyinaran 7 jam sebesar 40,37\%. Degradasi methyl orange berlangsung efektif dengan adanya sinar dibandingkan tanpa penyinaran. Reaksi fotodegradasi methyl orange mengikuti kinetika reaksi orde satu semu dengan nilai $k$ sebesar $0,0378 \mathrm{jam}^{-1}$.
\end{abstract}

Kata kunci : batu apung-semen, fotodegradasi, methyl orange, reaktor fixed bed

\begin{abstract}
The objectives of this research were to know the characterization of pumice stone and cement used in fixed bed reactor. The fixed bed used was made from pumice stone with a gluing cement in $5 \times 16 \times 16 \mathrm{~cm}$ stainless steel mold. Methyl orange photodegradation were carried out with $\mathrm{pH} \mathrm{1,2,3,4,5,6,7,8,9,10,11,} \mathrm{12,} \mathrm{13,} \mathrm{and}$ 14 and irradiated by 2 lamps of UV Sankyo Denky FT10T8BLB FL10BLB 10 W 325 $\mathrm{nm}$ for 1, 2, 3, 4, 5, 6 and 7 hours. Methyl orange was circulated at room temperature from its reservoir to fixed bed reactor by a pump with $6.89 \mathrm{~mL} / \mathrm{s}$. Pumice stone and
\end{abstract}


cement were analyzed by SEM EDX to know its characterization. Methyl orange concentration before and after photodegradation were measured by UV Visible Spectrophotometer Shimadzu 1240. The result showed that pumice stone has irreguler shape with the highest material is $\mathrm{Si}$ and cement has homogeneous granule with the highest material is $\mathrm{Ca}$. The best fotodegradation of methyl orange with UV irradiation at $\mathrm{pH} 3$. Methyl orange photodegradation follows pseudo first order kinetics with reaction constant 0,0378 hour $^{-1}$.

Keywords : fixed bed reactor, methyl orange, pumice stone-cement, photodegradation

\section{PENDAHULUAN}

Methyl orange merupakan salah satu zat warna sintetik yang termasuk dalam golongan azo. Zat warna ini banyak digunakan pada industri tekstil, makanan, kertas dan kulit. Senyawa ini juga digunakan sebagai indikator asam basa pada proses titrasi perubahan warna merah menjadi kuning pada kisaran pH 3,1-4,4 (Mehra and Sharma, 2012). Keberadaan senyawa golongan azo dalam limbah yang melebihi ambang batas sebesar $5 \mathrm{mg} / \mathrm{L}$ (Kep Men LH No 51 Tahun 1995) dapat menimbulkan terjadinya pencemaran lingkungan. Kasus pencemaran di industri tekstil yang pernah terjadi pada tahun 1930 seperti yang dilaporkan oleh Chung and Cernigla dalam Dwiasi dan Kurniasih (2007) telah mengakibatkan tejadinya alergi dan iritasi pada kulit.

Pengolahan limbah methyl orange yang dilakukan dengan cara fisika, biologi dan kimia telah dilaporkan oleh beberapa peneliti. Ketiga metode pengolahan tersebut, antara lain adsorpsi methyl orange dengan menggunakan kitosan (Sha et al., 2010; Umpuch and Sakaew, 2013), degradasi dengan menggunakan bakteri Pseudomonas sp (Shah et.al., 2013), Bacillus sp (Pourbabaee, 2005) serta fotodegradasi dengan menggunakan $\mathrm{TiO}_{2}$ (Mehra and Sharma, 2012; Su et al., 2013), katalis ZnO yang berukuran nano (Chen et al., 2011), Cr yang didoping pada ZnS (Eyasv et. al, 2013), nanopartikel besi bervalensi nol (Shih et al., 2010), dan tembaga termodifikasi (El-Moselhy, 2013). Hasil-hasil penelitian yang dilaporkan tersebut menunjukkan terjadinya penurunan konsentrasi methyl orange dalam limbah. Beberapa permasalahan yang ditemui pada saat melakukan proses pengolahan maupun setelah proses pengolahan yaitu terdapatnya limbah padatan baru yang mengandung methyl orange dengan menggunakan proses adsorpsi serta tingginya biaya operasional dan lamanya waktu untuk mendegradasi methyl orange dengan menggunakan bakteri. Penggunaan fotokatalis dalam proses degradasi metil oranye memang dapat meningkatkan jumlah metil oranye yang terdegradasi, namun pengambilan kembali katalis yang telah digunakan akan memerlukan waktu yang lebih lama dan tambahan biaya operasional.

Salah satu alternatif pemecahan masalah pengambilan kembali fotokatalis agar menjadi lebih mudah yaitu dengan cara melakukan imobilisasi katalis pada bahan 
pendukung seperti karbon aktif (Zainal et al., 2009), zeolit (Faghihian and Bahranifard, 2011), semen (Sopyan et al., 2011), serta Low Density Poly Ethylene (LDPE) dan kaca borosilikat (Prabhu and Priya, 2012). Bahanbahan pendukung yang telah digunakan dalam penelitian tersebut dilaporkan memiliki luas permukaan spesifik yang tinggi. Telah dilaporkan oleh Yuningrat dan Oviantari (2013) bahwa $\mathrm{TiO}_{2}$ yang diimobilisasi pada plat kaca dapat meningkatkan degradasi fenol dalam lindi. Plat kaca yang digunakan sebagai pendukung sangat mudah didapat. Selain itu, plat kaca memiliki sifat mudah ditembus cahaya, namun memiliki kelemahan sangat mudah pecah. Penggunaan bahan pendukung alami merupakan salah satu pertimbangan yang dapat dilakukan untuk mengganti penggunaan plat kaca. Bahan pendukung alami seperti semen putih, batu merah dan batu apung sangat mudah didapat dan harganya murah (Rachel et al., 2002). Batu apung diketahui memiliki porositas sekitar $85 \%$ dan luas spesifik yang tinggi. Sifatsifat batu apung tersebut dapat dimanfaatkan sebagai bahan pendukung fotokatalis $\mathrm{TiO}_{2}$. Penggunaan batu apung sebagai bahan pendukung $\mathrm{TiO}_{2}$ untuk mendegradasi zat warna methyl orange belum pernah dilaporkan hingga saat ini.

\section{METODE}

Alat-alat yang digunakan dalam penelitian ini yaitu neraca analitik, $\mathrm{pH}$ meter, spektrofotometer UV-Visible shimadzu 1240, XRD, FTIR, SEM, pompa, 2 buah lampu UV (Sankyo
Denky FT10T8BLB FL10BLB $10 \mathrm{~W}$ $325 \mathrm{~nm}$ ), selang, dan cetakan stainless steel. Bahan-bahan yang digunakan adalah batu apung, semen, metanol, $\mathrm{HNO}_{3}$, methyl orange, $\mathrm{HCl} 37 \%, \mathrm{NaOH}$, larutan bufer $(\mathrm{pH} \mathrm{1,} \mathrm{2,} \mathrm{3,} \mathrm{4,} \mathrm{5,} \mathrm{6,} \mathrm{7,} \mathrm{8,} \mathrm{9,}$ $10,11,12,13,14)$ dan $\mathrm{H}_{2} \mathrm{SO}_{4} 98 \%$. Semua bahan kimia yang digunakan berkualitas analisis dan buatan PT Merck Tbk. Instrumen yang digunakan adalah SEM EDX dan spektrofotometer UV Visibel Shimadzu 1240.

Methyl orange yang digunakan dalam penelitian ini merupakan kualitas pro analis. Penelitian ini diawali dengan karakterisasi batu apung dan semen dan pembuatan bed batu apung terimobilisasi $\mathrm{TiO}_{2}$. Selanjutnya, methyl orange dialirkan dalam reaktor fixed bed, serta diberikan sinar UV dengan variasi waktu 1, 2, 3, 4, 5, 6 dan 7 jam. Pengaruh $\mathrm{pH}$ dan waktu sirkulasi dipelajari untuk mengevaluasi efektivitas fotodegradasi methyl orange.

Morfologi batu apung dan semen beserta komposisi unsurnya disajikan dalam bentuk gambar. Penentuan methyl orange yang diperoleh dari setiap perlakuan disajikan dalam bentuk grafik. Grafik yang dibuat menyajikan pengaruh $\mathrm{pH}$ dan waktu sirkulasi terhadap efektivitas penurunan konsentrasi methyl orange.

\section{HASIL DAN PEMBAHASAN}

Batu apung yang digunakan sebagai bed untuk imobilisasi $\mathrm{TiO}_{2}$ diperoleh dari Desa Bungkulan Kecamatan Sawan Kabupaten Buleleng Bali. Keberadaan batu apung yang merupakan bahan galian industri golongan C di Desa Bungkulan sangat berlimpah. Sampel batu apung yang digunakan dalam penelitian ini tampak 
berwarna putih kecoklatan dengan gambar dan komposisi unsur seperti yang disajikan dalam Gambar 1a. Semen yang digunakan sebagai


(a)
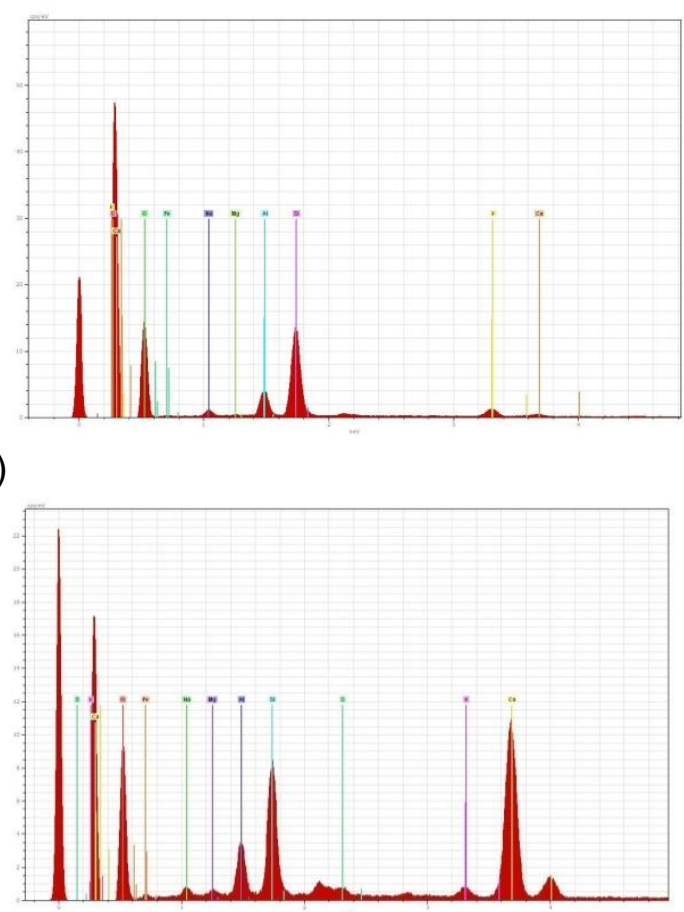

(b)

Gambar 1. Morfologi batu apung pembesaran 10000 kali beserta komposisi unsurnya (a) dan morfologi semen pembesaran 50000 kali beserta komposisi unsurnya (b)

Berdasarkan hasil analisis dengan menggunakan SEM EDX seperti yang disajikan pada Gambar 1a dapat diketahui bahwa batu apung yang diambil dari Desa Bungkulan Kecamatan Sawan Kabupaten Buleleng memiliki bentuk yang tidak beraturan. Unsur-unsur yang terkandung dalam batu apung memiliki komposisi $\mathrm{C}$ $48,75 \%$; O 41,44\%; $\mathrm{Na} 0,89 \%$; $\mathrm{Mg}$ 0,05\%; Al 1,94\%; Si 5,69\%; K 0,64\%; perekat merupakan semen portland dengan morfologi dan komposisi unsur seperti yang disajikan dalam Gambar $1 b$. 
dalam semen sebagai perekat adalah Ca. Perekat semen yang digunakan dalam cetakan memiliki bentuk yang homogen seperti butiran-butiran dengan komposisi unsur C 32,44\%; O 55,40\%; $\mathrm{Na} 0,37 \% ; \mathrm{Mg}$ 0,37\%; Al 1,03\%; Si 3,27\%; S 0,37\%; K 0,24\%; Ca 6,14\% dan $\mathrm{Fe}$ 0,38\%. Keberadaan unsurunsur $\mathrm{Ca}, \mathrm{Si}$, $\mathrm{Fe}$ dan $\mathrm{Al}$ yang terkandung dalam semen sangat mempengaruhi proses pengikatan semen dengan batu apung dan kekuatan tekan semen.

Batu apung yang digunakan dalam penelitian ini sangat mudah didapat. Sifat-sifat yang dimiliki batu apung yaitu luas permukaan spesifik yang tinggi dan ringan telah banyak digunakan sebagai bed filter, adsorben dan bahan pendukung dalam pengolahan air maupun limbah. Semen yang dalam penelitian ini digunakan sebagai perekat, juga dapat digunakan sebagai bahan pendukung. Cetakan yang digunakan terbuat dari stainless steel untuk mencegah terjadinya kontak antara limbah yang memiliki derajat keasaman rendah maupun tinggi dengan cetakan fixed bed.

Methyl orange yang dialirkan melalui fixed bed reaktor tanpa menggunakan sinar UV dapat terdegradasi sebesar 1,70\%. Pendegradasian ini dapat disebabkan oleh terjadinya proses adsorpsi methyl orange pada permukaan batu apung. Telah dilaporkan oleh Samarghandi et al. (2012) bahwa degradasi zat warna Acid Red 14 terjadi melalui proses adsorpsi pada permukaan batu apung kemudian interaksi elektrostatik antara ion $\mathrm{Si}^{2+}$ yang berasal dari $\mathrm{SiO}_{2}$ dalam batu apung dengan anion zat warna dari gugus sulfonat $\mathrm{DSO}_{3}$. Keberadaan ion $\mathrm{H}^{+}$pada suasana asam dapat meningkatkan kapasitas kation dari adsorben sehingga terjadi gaya elektrostatik yang kuat. Penurunan konsentrasi zat warna Acid Red 14 maksimum sebesar $90 \%$ terjadi pada $\mathrm{pH}$ 3.

Jenis sinar yang digunakan dalam penelitian ini adalah sinar sintetis berupa lampu UV. Lampu UV yang digunakan adalah black light blue dengan panjang gelombang $352 \mathrm{~nm}$ yang dikategorikan ke dalam UV A (315$400 \mathrm{~nm})$. UV A memiliki panjang gelombang terpanjang, tetapi intensitasnya lebih lemah dibandingkan sinar matahari yang dapat dikategorikan ke dalam UV B.

Penyinaran

dengan menggunakan panjang gelombang yang lebih besar (UV A) akan menghasilkan energi foton yang lebih kecil. Hal ini sesuai dengan Hukum Planck yang menyatakan bahwa besarnya energi berbanding terbalik dengan panjang gelombang suatu sinar. Oleh karena itu, untuk sinar ultraviolet yang memiliki panjang gelombang kurang dari $300 \mathrm{~nm}$ akan memancarkan sinar dengan energi yang lebih besar dari $400 \mathrm{~kJ} / \mathrm{mol}$ (Wardle, 2009).

Pengaruh $\mathrm{pH}$ larutan methyl orange dan waktu sirkulasi terhadap methyl orange yang terdegradasi disajikan dalam Gambar 2. 


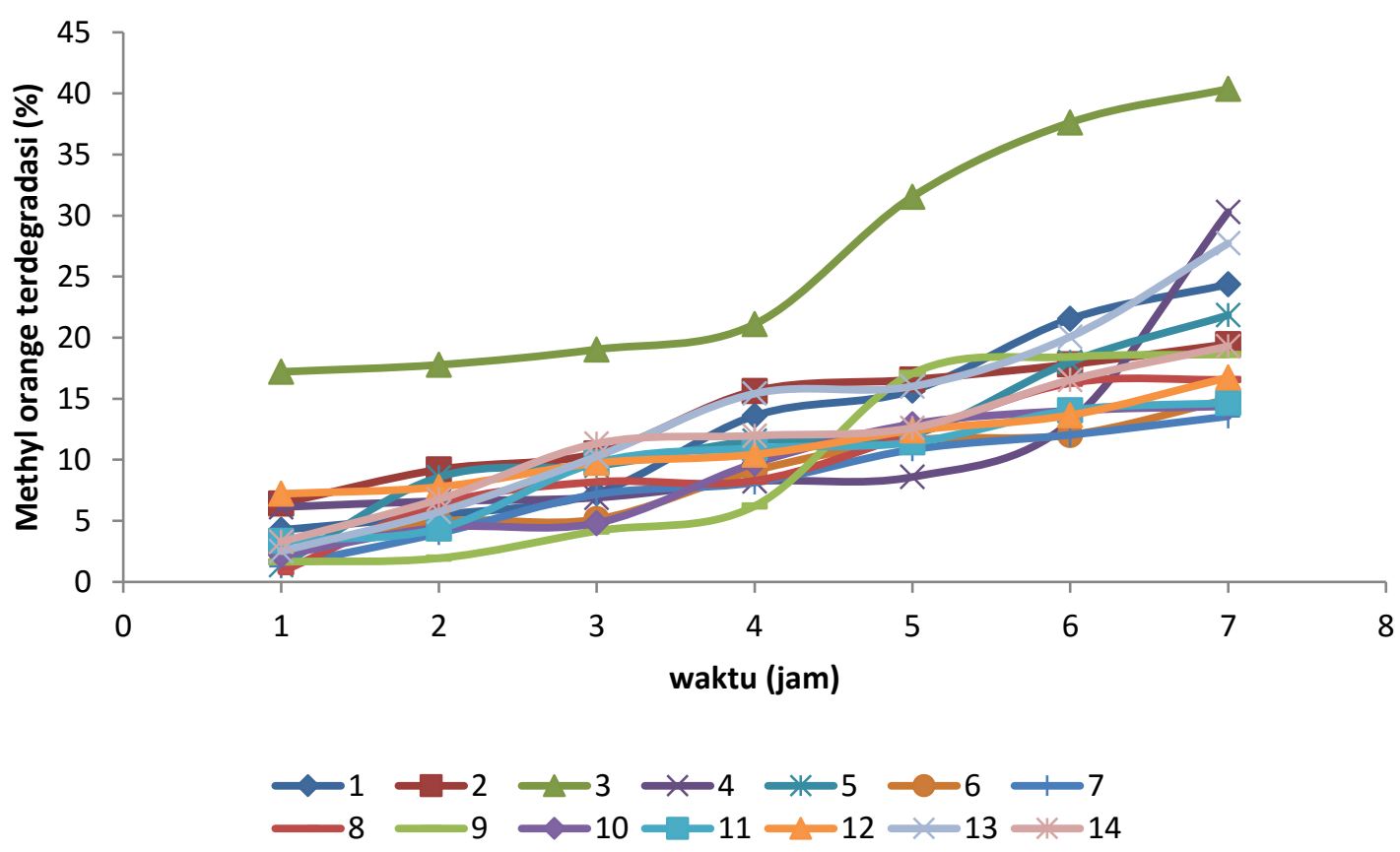

Gambar 2. Pengaruh waktu dan $\mathrm{pH}$ pada fotodegradasi methyl orange dengan menggunakan bed batu apung semen pada $\mathrm{pH} 1,2,3,4,5,6,7,8,9,10,11,12$, 13,14

Proses fotodegradasi methyl orange dengan menggunakan reaktor fixed bed batu apung semen berlangsung optimum pada $\mathrm{pH} 3$ seperti yang disajikan pada Gambar 2. Semakin lama waktu penyinaran pada proses fotodegradasi methyl orange maka semakin banyak methyl orange yang terdegradasi. Fotodegradasi methyl orange yang dijalankan pada berbagai $\mathrm{pH}$ mencapai efektivitas yang maksimum untuk waktu penyinaran selama 7 jam. Sebanyak 40,37\% methyl orange telah terdegradasi untuk $\mathrm{pH}$ larutan methyl orange 3 dan waktu penyinaran selama 7 jam.
Penurunan konsentrasi methyl orange dengan semakin lamanya waktu penyinaran dapat disebabkan oleh banyaknya methyl orange yang teradsorpsi pada permukaan batu apung maupun teroksidasi oleh radikal hidroksil pada waktu yang sama. Mekanisme pendegradasian methyl orange dalam reaktor fixed bed batu apung-semen dengan menggunakan sinar dan tanpa penyinaran (gelap) didukung oleh efektivitas degradasi methyl orange seperti yang disajikan dalam Gambar 3 . 


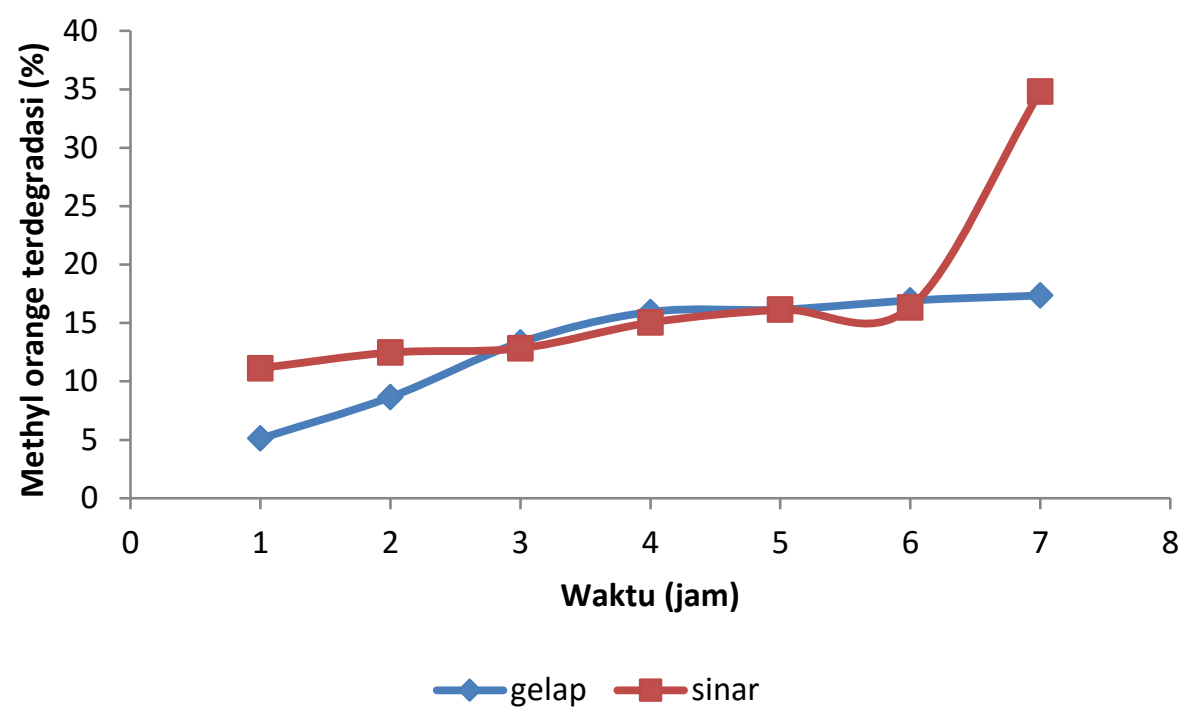

Gambar 3. Pengaruh waktu reaksi terhadap degradasi methyl orange dalam keadaan gelap maupun dengan adanya sinar

Adanya sinar menyebabkan lebih banyak methyl orange yang terdegradasi dibandingkan tanpa sinar (gelap) seperti yang disajikan pada Gambar 3. Degradasi methyl orange dalam keadaan gelap dapat terjadi melalui proses adsorpsi pada permukaan batu apung. Adanya sinar dalam sistem reaksi lebih mengefektifkan methyl orange yang terdegradasi. Hal ini disebabkan oleh adanya interaksi antara methyl orange dan foton yang dihasilkan oleh sinar UV.
Oleh karena itu, selain terjadi proses adsorpsi, juga terjadi proses fotodegradasi terhadap methyl orange.

Reaksi fotodegradasi senyawa organik mengikuti mekanisme reaksi order satu semu. Hubungan antara waktu reaksi degradasi methyl orange terhadap In $\left(\mathrm{C}_{0} / \mathrm{C}\right)$ disajikan dalam Gambar 4. Harga konstanta kecepatan reaksi fotodegradasi senyawa organik (k) dapat diperoleh dari grafik yang terdapat pada Gambar 4 yaitu melalui slope persamaan garis linearnya. 


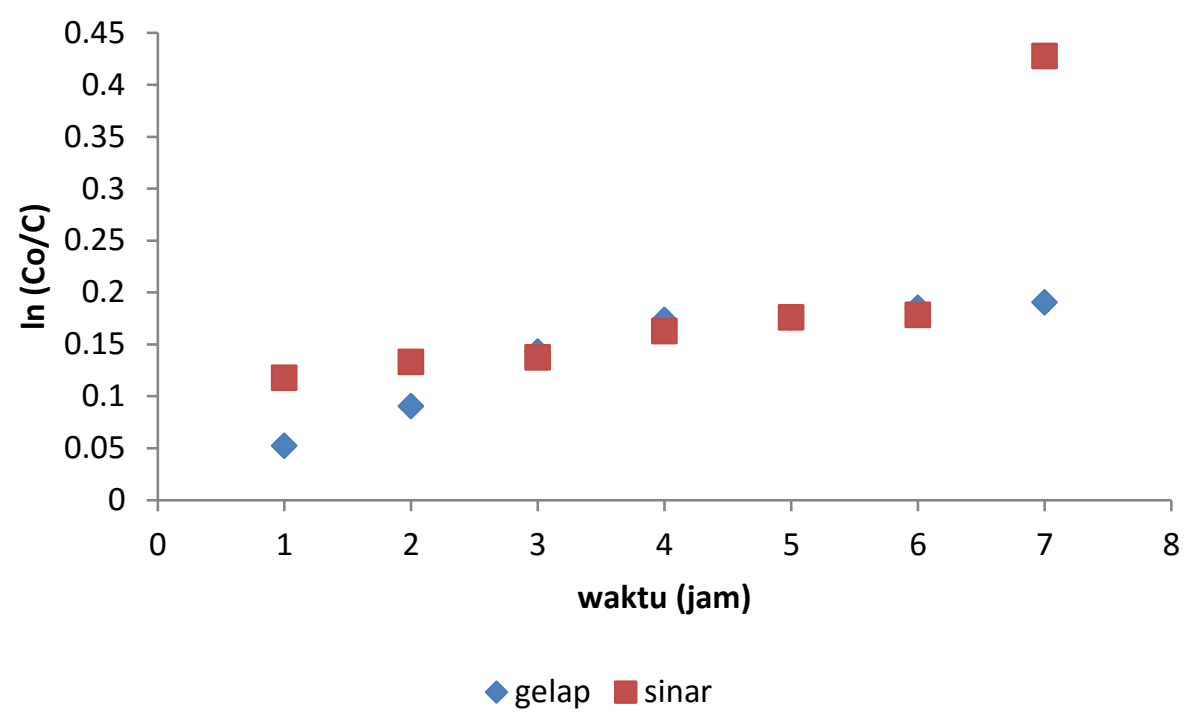

Gambar 4. Hubungan antara waktu reaksi degradasi methyl orange lawan In $\left(\mathrm{C}_{0} / \mathrm{C}\right)$

Nilai konstanta kecepatan reaksi (k) untuk sistem reaksi degradasi methyl orange tanpa sinar (gelap) diperoleh sebesar 0,0227 jam $^{-1}$ sedangkan untuk sistem reaksi dengan menggunakan sinar sebesar 0,0378 jam $^{-1}$. Reaksi degradasi methyl orange dalam reaktor fixed bed batu apung-semen dengan adanya sinar berlangsung lebih cepat dibandingkan dalam keadaan gelap. Hal ini disebabkan oleh terjadinya proses adsorpsi pada permukaan batu apung dan fotodegradasi yang sinergis dalam sistem reaksi. Keberadaan radikal hidroksil yang dihasilkan dari fotolisis air dengan sinar dapat mendegradasi methyl orange menjadi senyawa yang lebih sederhana dan ramah terhadap lingkungan.

\section{SIMPULAN}

Berdasarkan pembahasan yang telah dilakukan, dapat disimpulkan yaitu batu apung memiliki bentuk yang tidak teratur dengan kandungan unsur yang tertinggi adalah $\mathrm{Si}$ sedangkan semen yang digunakan sebagai perekat memiliki bentuk seperti butiran yang homogen dengan kandungan unsur tertinggi yaitu $\mathrm{Ca}$. Fotodegradasi methyl orange dengan menggunakan reaktor fixed bed batu apung-semen berlangsung optimum pada $\mathrm{pH} 3$ untuk waktu penyinaran selama 7 jam dengan efektivitas sebesar 40,64\%. Adanya sinar dalam sistem reaksi lebih mengefektifkan methyl orange yang terdegradasi dibandingkan dalam keadaan gelap. Kinetika reaksi fotodegradasi methyl orange mengikuti reaksi orde satu semu dengan nilai konstanta kecepatan reaksi sebesar 0,0378 jam $^{-1}$.

\section{UCAPAN TERIMA KASIH}

Terima kasih kepada Direktorat Penelitian dan Pengabdian pada 
Masyarakat Direktorat Jendral Pendidikan Tinggi Kementerian Pendidikan dan Kebudayaan melalui Hibah Bersaing Tahun 2015 dengan SPK Nomor: 023.04.1.673453/2015 Tanggal 14 November 2014.

\section{DAFTAR PUSTAKA}

Chen, C., Liu, J., Liu, P and Yu, B. 2011. Investigation of Photocatalytic Degradation of Methyl Orange by Using Nano-Sized ZnO Catalyst. Advances in Chemical Engineering and Science $1: 9-14$

Dwiasi, D.W., dan Kurniasih, M. 2007 Studi Degradasi Zat Pewarna Azo Metil Oranye Menggunakan Ferrat $\left(\mathrm{FeO}_{4}{ }^{2-}\right)$. Molekul 2 (1): 1520.

El-Moselhy, M.M., Mahmoud, N.M.R., and Emara, M.M. 2013. Copper Modified Exchanger For The Photodegradation of Methyl Orange Dye. Desalination and Water Treatment : 1-10.

Eyasv, A., Yadav, O.P., and Bachheti, R.K. 2013. Photocatalytic Degradation of Methyl Orange Dye Using $\mathrm{Cr}$ Doped ZnS Nanoparticles Under Visible Radiation. International Journal of ChemTech Research 5(4) : 1452-1461.

Faghihian, $\mathrm{H}$ and Bahranifard, A. 2011. Application of $\mathrm{TiO}_{2}$-Zeolite As Photocatalyst

Photodegradation of Some Organic Pollutants. Iranian Journal of Catalysis $1: 45-50$.

Mehra , M and Sharma, T.R. 2012. Photocatalytic Degradation of Two Commercial Dyes in Aqueous Phase Using
Photocatalyst $\mathrm{TiO}_{2}$. Advances in Applied Science Research 3(2) : 849-853

Pourbabaee, A.A., Malekzadeh, F. Sarbolouki, M.N and Mohajeri, A. 2005. Decolorization of Methyl Orange (As A Model Azo Dye) By The Newly Discovered Bacillus sp. Iran.J.Chem.Chem.Eng. 24 (3)

Prabu, K and Priya, S. 2012. Comparison of Efficiency of Solar Photocatalytic Degradation of Phenol Using UV Transparent Materials. International Journal of Engineering Science and Technology 4(4) : 1421-1425.

Rachel, A., Lavedrine, B. Subrahmanyam, M., Boule, P. 2002. Use of Porous Lavas as Supports of Photocatalysts. Catalysis Communications 3 : 165-171.

Samarghandi, M.R., Zarrabi, M., Noori

Sepehr, M., Panahi, R., and

Foroghi, M. 2012. Removal of Acid Red 14 by Pumice Stone As A Low Cost Adsorbent: Kinetic and Equilibrium Study. Iran. J. Chem. Chem. Eng. 31 (3) : 1927.

Sha, T.K., Bhoumik, N.C., Karmaker, S., Ahmed, M.G., Ichikawa, H., and Fukumori, Y. 2010. Adsorption of Methyl Orange Onto Chitosan for Aqueous Solution. J.Water Resource and Protection 2 : 898906.

Shah, M.P., Patel, K.A., Nair, S.S., and Darjl, A.M. 2013. Microbial Decolorization of Methyl Orange Dye by Pseudomonas spp ETLM. International Journal of 
Environmental Bioremediation and Biodegradation 1 (2) : 54-59.

Shih, Y., Tso, C., and Tung, L. 2010. Rapid Degradation of Methyl Orange with Nanoscale Zerovalent Iron Particles. J. Environ.Eng.Manag. 20(3) : 137143.

Sopyan,I., Hafizah., Jamla, P. 2011. Immobilization of $\mathrm{TiO}_{2}$ with Cement : Photocatalytic of Phenol and Its Kinetics Studies. Indian Journal of Chemical Technology 18 : 263-270.

Su, Y., Yang, Y., Zhang, H., Xie, Y., Wu, Z., Jiang, Y., Fukata, N., Bando, Y., and Wang, Z.L. 2013. Enhanced Photodegradation of Methyl Orange With $\mathrm{TiO}_{2}$ Nanoparticles Using A Triboelectric Nanogenerator. Nanotechnology 24 : 295401.

Umpuch, C. and Sakaew, S. 2013. Removal of Methyl Orange From Aqueous Solutions by Adsorption Using Chitosan Intercalated
Montmorillonit." Songklanakaria J.Sci.Technol. 35(4) : 451459.

Wardle, Brian. Principles and Applications of Photochemistry. United Kingdom: John Wiley \& Sons, 2009.

Yuningrat, N.W dan Oviantari, M.V. 2013.Fotodegradasi Fenol Pada Lindi dengan Menggunakan Plat Kaca Terimobilisasi $\mathrm{TiO}_{2}$ pada Reaktor Batch. Prosiding Seminar Nasional Riset Inovatif I Lembaga Penelitian Universitas Pendidikan Ganesha, Singaraja Bali, 2013.

Zainal, Z., Hui, L.K., Hussein, M.Z., Abdullah, A.H., and Hamadneh I.R. 2009. Characterization of $\mathrm{TiO}_{2}$-Chitosan/Glass Photocatalyst For The Removal of A Monoazo Dye via Photodegradation-Adsorption Process. Journal of Hazardous Materials 164 : 138-145. 